\title{
Application of CAPS markers for diversity assessment in grass pea (Lathyrus sativus L.)
}

\section{Eleni Shiferaw ${ }^{1,2 *}$, Enrico Porceddu ${ }^{2,3}$, Enrico Pé2 \& Maharajah Ponnaiah ${ }^{2,4}$}

${ }^{1}$ Ethiopian Biodiversity Institute, P.O. Box 30726, Addis Ababa, Ethiopia

${ }^{2}$ Scuola Superiore Sant'Anna, Piazza Martiri della Liberta 33, 56127 Pisa, Italy

${ }^{3}$ University of Tuscia, Via S. C. De Lellis 01100, Viterbo, Italy

${ }^{4}$ Pierre and Marie Curie University, UPMC-Paris 6, Developmental Biology Laboratory, UMR 7622, Paris, France

*corresponding author (e-mail: teleni08@gmail.com)

\begin{abstract}
Genetic diversity among 20 Lathyrus sativus L. accessions from Ethiopia was investigated by using Cleaved Amplified Polymorphic Sequence (CAPS) markers. Genetic diversity statistics showed presence of a moderate level of genetic variation in the analysed accessions $(\mathrm{P}=69.77 \%, \mathrm{Hs}=0.278)$. Analysis of genetic differentiation showed existence of a low level of differentiation between accessions, which accounted for only $7 \%$ of the total variation and most of the variation was due to differences among individuals within accessions (93\%). Both cluster and principal coordinate analyses revealed minimal grouping of accessions based on geographical origin implying that local varieties of grass pea with different genetic backgrounds were distributed among various administrative regions in Ethiopia. The CAPS markers employed in our study demonstrated the utility of such markers for genetic diversity assessment in grass pea.
\end{abstract}

Key words: CAPS markers, genetic diversity, Lathyrus sativus

\section{Introduction}

Grass pea (Lathyrus sativus L.) is a legume crop used as human food and animal feed in different parts of the world, with specific importance in countries such as Ethiopia, India and Bangladesh (Campbell 1997). It is adapted to grow under extremely dry conditions, as well as on land subjected to flooding (Smartt et al. 1994). It can grow in a wide range of soil types with few agricultural inputs, and, when compared to other legumes, it has better resistance to many disease agents and pests (Campbell 1997). Its nutritional composition is comparable to other legume crops, such as field pea, which makes grass pea a good source of protein and starch (Vaz Patto et al. 2006). Grass pea is an important crop of economic significance for Ethiopia. Its ability to grow in harsh environmental conditions makes the crop preferable in many regions of the country where low input farming system is practiced. Currently it is cultivated on $9.6 \%$ of the total pulse production area of the country (CSA 2016).

Understanding the distribution and the structure of intraspecific diversity is essential for efficient conservation, management, and utilization of genetic resources. Different types of molecular tools are being used to evaluate genetic polymorphism in crop plants to achieve this purpose. However, with the exception of a few species, many legume crops have received little attention from advances made in molecular and genomic research (Varshney et al. 2007). This problem is also evident in crops like grass pea that are important for subsistence of local communities but do not have wider usage.

Polymorphic markers have been an important factor for diversity analysis and other genetic studies in various species. Among the molecular tools, diversity analysis on grass pea has been carried out by using RAPD (Croft et al. 1999), AFLP (Tavoletti \& Iommarini 2007) and RFLP (Chtourou-Ghorbel et al. 2001). ISSR markers 
have been utilized to evaluate genetic relationships among different species in the Lathyrus genus (Belaid et al. 2006). Recently, however, progress has been made and additional molecular markers, which include EST-SSRs (Shiferaw et al. 2012; Sun et al. 2012) and genomic SSRs (Lioi \& Galasso 2013; Yang et al. 2014; Wang et al. 2015) were developed to support genetic and genomic research on the species.

CAPSs (Cleaved Amplified Polymorphic Sequences) are markers, which are the result of restriction digestion of locus-specific PCR amplicons with appropriate restriction enzymes. Mutation in the restriction site creates or disrupts a restriction enzyme recognition site resulting in changes in the patterns of restriction fragments revealing polymorphisms (Konieczny \& Ausubel 1993). CAPS markers have been successfully used for diversity analysis in different plant species (Tsumura \& Tomaru 1999; Tsumura et al. 2007; Barth et al. 2002); variety identification (Hu et al. 2014), construction of linkage maps (Konovalov et al. 2005), and for marker assisted selection (Akashi et al. 2001; Gutierrez et al. 2006).

Publicly available Expressed Sequence Tags (ESTs) provide an excellent source for developing different types of DNA markers. These sources are useful especially for species whose genetic and genomic studies are very limited despite their potential and wider use in few countries. Sequence-derived markers have been published, which were developed by converting L. sativus defense-related ESTs into mapable genetic markers (Skiba et al. 2003), and some of these markers have been converted to CAPS markers. The objective of the present study is, hence, to evaluate the application of these markers for diversity studies in grass pea and to demonstrate the possibility of utilization of such markers for diversity assessment so that they can be exploited as alternative tools by themselves or in combination with other markers in species that lack adequate molecular tools.

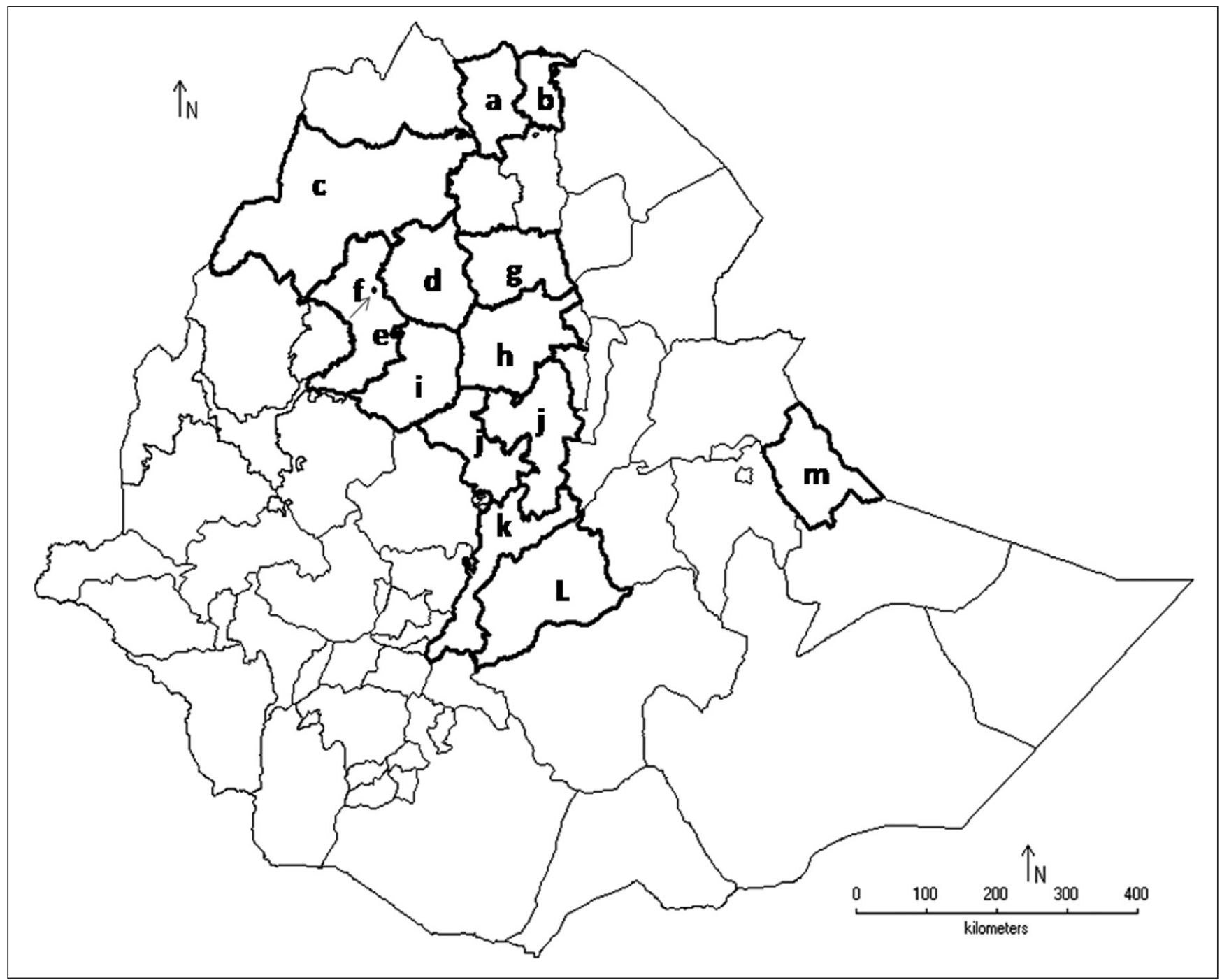

Fig. 1. Map of Ethiopia showing geographic origins of the grass pea accessions used in this study

Explanations: a - Central Tigray, b - East Tigray, c - North Gonder, d - South Gonder, e - West Gonder, f - Bahir Dar Sp., g - North Welo, h - South Welo, i - East Gojam, j - North Shewa, k - East Shewa, 1-Arsi, M - Jijiga 


\section{Material and methods}

\subsection{Plant material}

Twenty grass pea accessions were obtained from the genebank of Ethiopian Biodiversity Institute; EBI/ Ethiopia. They were chosen to represent different growing regions (Fig. 1). From each accession, twenty seeds were grown in a greenhouse and 15 randomly chosen individual plants were used for DNA extraction and diversity assessment.

\subsection{DNA isolation and CAPS assay}

Leaf samples were collected from two-week old grass pea seedlings. Genomic DNA was extracted with a GenElute Plant Genomic DNA Miniprep Kit (SigmaAldrich, St. Louis, MO). DNA quality and quantification were estimated using 1\% agarose gel electrophoresis and ethidium bromide staining, utilising lambda DNA as a reference.

We assayed 10 published STS primer pairs (Table 1). PCR amplification was performed in a $25 \mu \mathrm{L}$ reaction volume containing: $5 \mathrm{X}$ PCR buffer, $0.2 \mathrm{mM}$ each of dNTPs, $0.4 \mu \mathrm{M}$ of forward and reverse primers, 1 unit of GoTaq ${ }^{\circledR}$ DNA polymerase (Promega), and $40 \mathrm{ng}$ of genomic DNA. Cycle conditions were as follows: initial denaturation at $94^{\circ} \mathrm{C}$ for $5 \mathrm{~min}$, followed by 30 cycles with denaturing at $94^{\circ} \mathrm{C}$ for $45 \mathrm{~s}$, annealing at optimal annealing temperature (varied with primers) for $1 \mathrm{~min}$, extension at $72^{\circ} \mathrm{C}$ for $1 \mathrm{~min}$, and a final extension at $72^{\circ} \mathrm{C}$ for $10 \mathrm{~min}$. Single monomorphic amplified products were digested with appropriate restriction endonucleases in a $10 \mu \mathrm{l}$ total reaction volume. The reaction mix contained: $5 \mu \mathrm{L}$ of PCR product, $1 \mu \mathrm{L}$ restriction enzyme buffer, 1 unit restriction enzyme, and, when applicable, Bovine Serum Albumin (BSA) in a final concentration of $0.1 \mathrm{mg} / \mathrm{mL}$. Amplicons and digested PCR products were resolved on $2 \%$ agarose gel in $1 \times$ TBE, stained with ethidium bromide and visualized with Gel Doc EQ ${ }^{\mathrm{TM}}$ (Bio-Rad). Consistency of results was assessed by analyzing random samples twice.

\subsection{Data analysis}

Results from the restriction digestion of the amplified products were transformed into binary data corresponding to the presence (1) or absence (0) of a specific fragment. The resulting binary data matrix

Table 1. Characteristics of CAPS markers tested and used for diversity assessment in grass pea

\begin{tabular}{|c|c|c|c|c|c|c|}
\hline $\begin{array}{c}\text { Primer } \\
\text { name }\end{array}$ & NCBI acc. no. & $\begin{array}{l}\text { Forward }(\mathrm{F}) \text { and reverse }(\mathrm{R}) \\
\text { Primer sequence }\left(5^{\prime}-3 \text { ') }\right.\end{array}$ & $\mathrm{T}_{\mathrm{a}}\left({ }^{\circ} \mathrm{C}\right)$ & $\begin{array}{l}\text { Restriction } \\
\text { Enzyme used }\end{array}$ & $\begin{array}{l}\text { Size of digested } \\
\text { PCR product } \\
\text { (bp) }\end{array}$ & $\begin{array}{c}\text { No. of } \\
\text { polymorphic } \\
\text { bands after } \\
\text { digestion }\end{array}$ \\
\hline 159 & DY396299 & $\begin{array}{l}\text { F: GCTTGAAGGGTTTTGATGGT } \\
\text { R: ACAGAGGTTTATCGTCATTTTTCTC }\end{array}$ & 58.3 & Hae III & 300 & 3 \\
\hline 351 & DY396332 & $\begin{array}{l}\text { F: GGGACCAAACAAAACCAAAA } \\
\text { R: TCAGTAAGTAGCCAAGCCAATC }\end{array}$ & 56 & Dde I & 1100 & 6 \\
\hline 524 & DY396349 & $\begin{array}{l}\text { F: GAGGGCCATTGTGCAAGT } \\
\text { R: TCCCATTTAAGAGGCTTCACC }\end{array}$ & 62.6 & $M n l \mathrm{I}$ & 270 & 2 \\
\hline 753 & DY396385 & $\begin{array}{l}\text { F: CTGATGAGAAGTTCACTCGTTTG } \\
\text { R: CTCCAGCACCAAATCCATAA }\end{array}$ & 59 & $R s a \mathrm{I}$ & 600 & 3 \\
\hline 81 & DY396281 & $\begin{array}{l}\text { F: GGTGACAAATACTGCAACTGG } \\
\text { R: ACGAAATGATATGCCTTGTTTT }\end{array}$ & 56.4 & Hae III & 250 & 2 \\
\hline 1005 & DY396430 & $\begin{array}{l}\text { F: ACCTTGTTCTCCCAGCTCTC } \\
\text { R: GGCCAACTGCCTTATTCAAA }\end{array}$ & 64 & $R s a \mathrm{I}$ & 1100 & 6 \\
\hline 2 & DY396260 & $\begin{array}{l}\text { F: CTGAGCTGGTTGGTGTGA } \\
\text { R: ATTGAAGGGAAAAGAAAAGACA }\end{array}$ & 64 & ApoI, Mnl I & 320 & NP \\
\hline 59 & DY396276 & $\begin{array}{l}\text { F: CAAACACACATAGCATATTAAGTGAA } \\
\text { R: CCATAAATGAGAAAGAAAATGGA }\end{array}$ & 58.3 & Hinf I, Dde I & 600 & NP \\
\hline 612 & DY396358 & $\begin{array}{l}\text { F: AACCGCCGATGTGCT TTT } \\
\text { R: TTTTCCCTTGGTGATTTTGG }\end{array}$ & 54 & Rsa I, Hinf I & 560 & NP \\
\hline 761 & DY396389 & $\begin{array}{l}\text { F: GATGCTTCAGTGTTGTTTGGT } \\
\text { R: ATACATTTTTATTTTATGGTAGATGCC }\end{array}$ & 58.3 & $\operatorname{Hinf} I, M n l I$ & 500 & NP \\
\hline
\end{tabular}

Explanations: Ta-optimum annealing temperature, bp-base pair, NP-Not polymorphic 


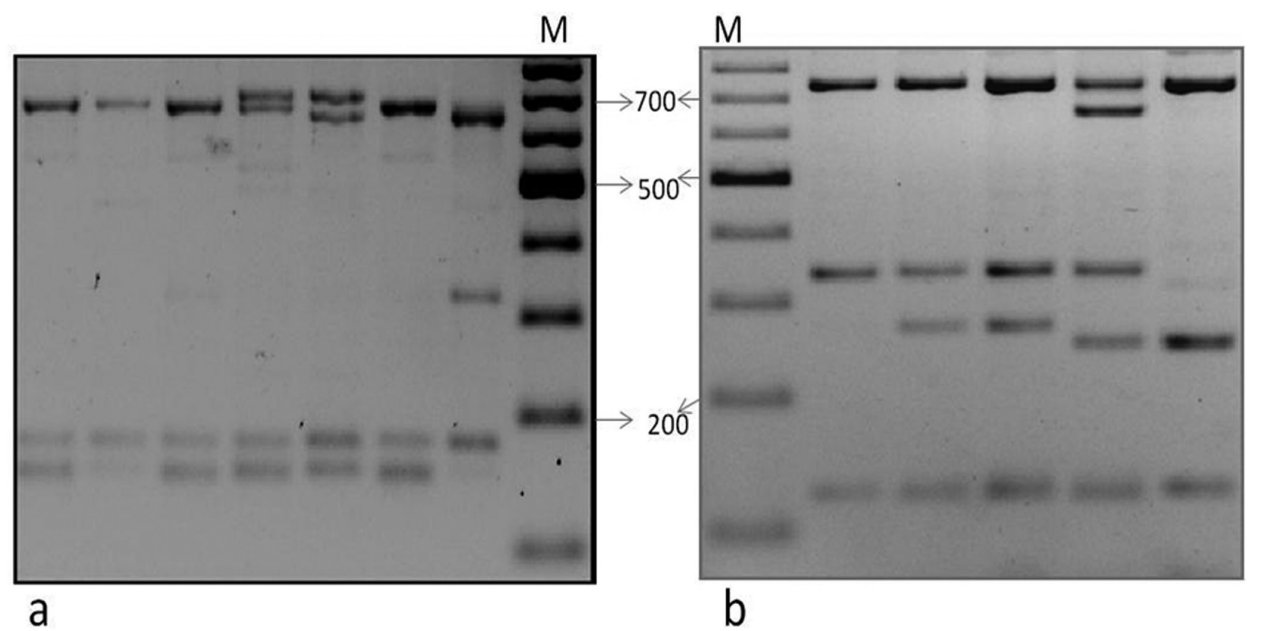

Fig. 2. CAPS polymorphism detected in grass pea accession using primer 1005 digested with Rsa I (a) and primer 351 digested with Dde I (b). $\mathrm{M}$ - Molecular weight marker (100bp)

for the 300 individuals was used to perform genetic diversity measures. Gene diversity was analysed by means of the Bayesian estimate of gene diversity, $h s$, using Hickory; Version 1.1 (Holsinger \& Lewis 2006) using the default parameters; a burn-in period of 5,000 iterations, a run of 25,000 iterations and a thinning factor of 5. Each model was run five times to ascertain consistency and average values of the runs were used for model comparison. Genetic differentiation was determined using $\theta^{\text {II }}$, a statistics similar to Nei's Gst. Percentage of polymorphic bands $(\mathrm{Pb})$ and Principal Coordinate Analysis (PCoA) was performed using GenAlEx 6.5 (Peakall \& Smouse, 2012). An unweighted pair group method with arthimetic mean (UPGMA) tree was produced with Nei's genetic distance using TFPGA version 1.3 (Miller 1997).

\section{Results}

Primers for our larger study were selected based on reproducibility and polymorphic patterns from initial screening on four accessions from different zones. Out of the 10 STS markers we assayed, six were polymorphic when digested with appropriate restriction enzymes (Fig. 2, Table 1), and they produced a total of 22 bands on the total analyzed samples.

\subsection{Diversity and population structure}

The DIC (Deviance Information Criterion), Dbar (measure of how well the model fits the data), Dhat and $\mathrm{pD}$ (approximate number of parameters being estimated) run in Hickory were interpreted following the recommendations given in the manual (Holsinger \& Lewis 2006) to estimate the best fit model among the available models. The DIC and $\mathrm{pD}$ values were lower in the Full model than other models and this model was used for estimating gene diversity.

The average gene diversity estimates (hs) was 0.278 \pm 0.005 (Table 2 ). The highest diversity was observed in accessions 7 and 14 from East Shewa and North Gondar zones, respectively, and the lowest variation was observed in accession 13 from the East Gojam zone. The percentage of polymorphic bands in the accessions averaged $69.77 \%$ and it ranged from $54.55 \%$ to $81.82 \%$. Analysis of differentiation among accessions was done using the free model, which does not estimate $\mathrm{f}$ (the within-accession inbreeding coefficient). The most relevant statistics $\left(\theta^{\text {II }}\right)$, directly comparable to estimates of Fst, gave a mean differentiation value of $0.068 \pm 0.014$.

\subsection{Cluster and Principal Coordinate analysis}

The genetic relationship among the 20 grass pea accessions was analysed on the basis of the Nei (1972) genetic distance (Fig. 3). The result showed that, at similarity coefficient value of 0.5 , the accessions were divided into five groups. Group I and IV contained one accession each, while the rest of the groups contained three to six accessions. Members of different accessions were grouped together and the overall clustering pattern did not follow the grouping of accessions according to their geographic origins. However, there were cases where accessions from the same origin were grouped together such as samples from Tigray (accession 5, 2 and 18). A close relationship between accessions from Tigray and the neighboring zone Gonder was also observed (group V).

Principal coordinate analysis ( $\mathrm{PCoA})$ on the basis of genetic distance was also used to visualize genetic association of accessions, which is primarily explained by the first two principal coordinates. The first and 
Table 2. List of analysed accessions with geographic origin, percentage of polymorphic bands $(\mathrm{Pb})$, and gene diversity (hs)

\begin{tabular}{cllcr}
\hline Accession code & Accession no. & Administrative Zone & hs & $\mathrm{Pb}(\%)$ \\
\hline 1 & 46019 & North Shewa & 0.276 & 63.64 \\
2 & 234043 & Central Tigray & 0.288 & 68.18 \\
3 & 236700 & Bahir Dar, Gojam & 0.272 & 54.55 \\
4 & 235018 & North Welo & 0.275 & 63.64 \\
5 & 238241 & Central Tigray & 0.287 & 72.73 \\
6 & 238945 & West Gojam & 0.291 & 72.73 \\
7 & 238955 & East Shewa & 0.295 & 77.27 \\
8 & 236562 & East Shewa & 0.293 & 81.82 \\
9 & 231325 & Arsi & 0.272 & 63.64 \\
10 & 238931 & South Gonder & 0.262 & 68.18 \\
11 & 236568 & North Shewa & 0.260 & 59.09 \\
12 & 46106 & Welo & 0.278 & 77.27 \\
13 & 46015 & East Gojam & 0.259 & 59.09 \\
14 & 238929 & North Gonder & 0.295 & 81.82 \\
15 & 215706 & South Welo & 0.281 & 72.73 \\
16 & 46050 & East Gojam & 0.272 & 72.73 \\
17 & 215246 & South Welo & 0.278 & 81.82 \\
18 & 207497 & East Tigray & 0.279 & 77.27 \\
19 & 212742 & South Gonder & 0.277 & 72.73 \\
20 & 241143 & Jijiga, Harerge & 0.265 & 54.55 \\
Mean & & & $0.278 \pm 0.005$ & $69.77 \pm 1.96$ \\
\hline
\end{tabular}

second coordinates extracted $20.06 \%$ and $15.23 \%$ of the total molecular variation, respectively. The individual samples belonging to different accessions formed no distinct groups based on accessions. Similar to the cluster analysis, PCoA also showed no clear separation of the populations based on geographic origins (Fig. 4).

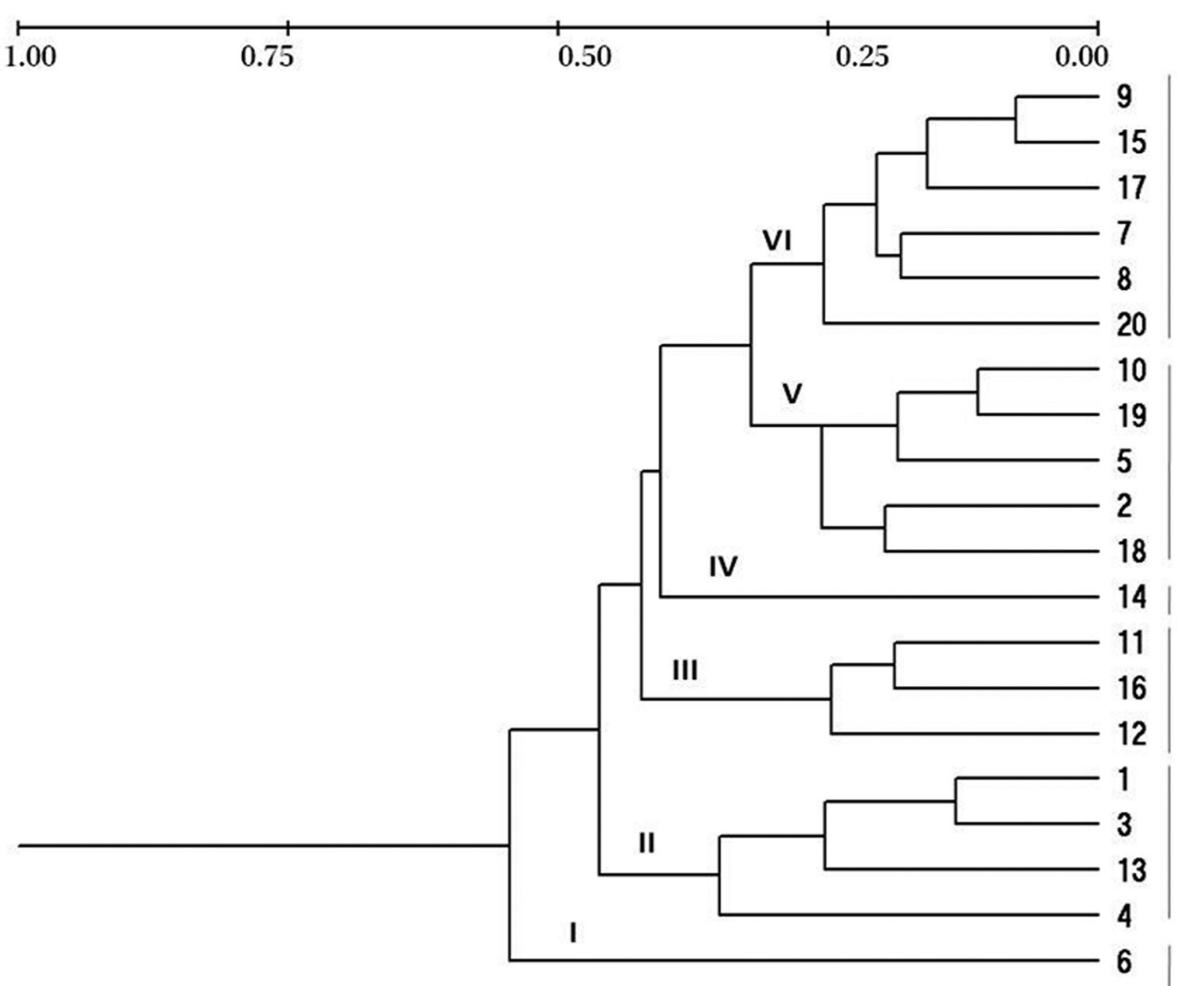

Fig. 3. Unweighted pair group with arithmetic mean (UPGMA) dendrogram based on Nei's genetic distance between 20 grass pea accessions with six CAPS markers 
Principal Coordinates (PCoA)

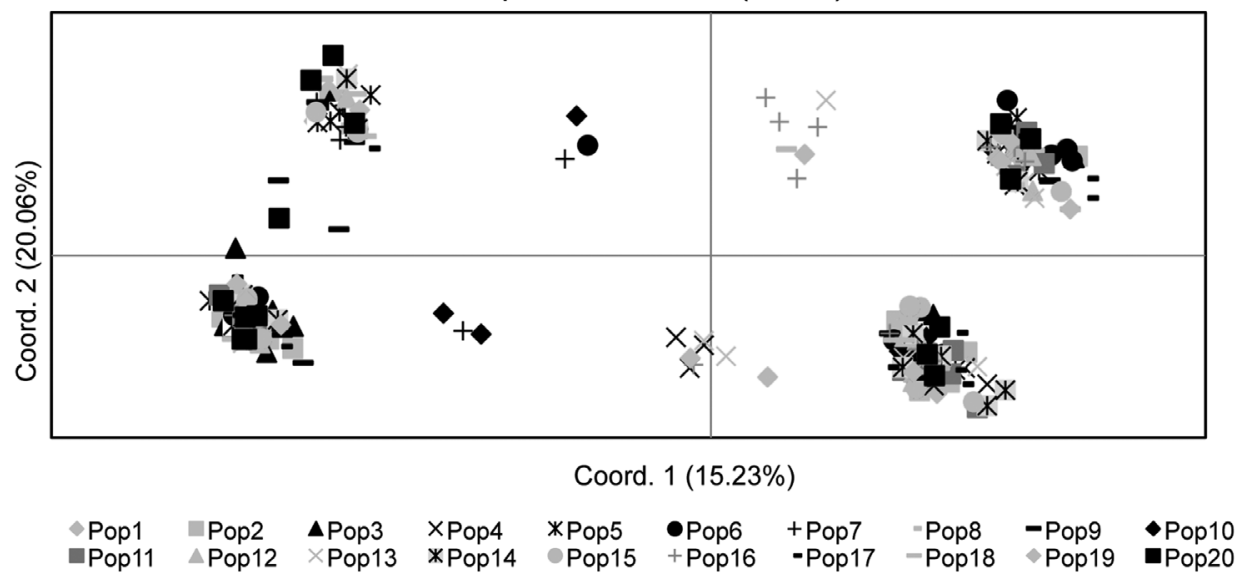

Fig. 4. Association among 20 accessions (populations 1-20) of grass pea revealed by principal coordinate analysis

\section{Discussion}

CAPS markers, developed by converting L. sativus ESTs into genetic markers by Skiba et al. 2003, were used for diversity assessment in accessions of the same species. The mean gene diversity level $(\mathrm{hs}=0.278)$ indicates presence of a moderate level of diversity among the analysed accessions. Previous studies on grass pea accessions from Ethiopia reported presence of significant variation using morphological markers (Tadesse \& Bekele 2003), while Chowdhury \& Slinkard (2000) reported a relatively lower level of diversity among grass pea accession collected from Ethiopian region by using isozyme markers. Seven L. Sativus based EST-SSR markers resulted in a total of 25 alleles and the six CAPS markers used in this study resulted in 22 polymorphic bands after restriction digestion. EST-SSR markers revealed a higher level of diversity $(\mathrm{He}=0.419)$ on Ethiopian accessions (Shiferaw et al. 2012), which shows a better discriminating capacity of these markers than the CAPS markers. However, the level of polymorphism and gene diversity observed using CAPS markers show that these markers are also informative tools that can be used independently or in combination with other types of markers.

Cluster analysis and PCoA resulted in the grouping of accessions and individual plants irrespective of their region of origin implying that local varieties of grass pea with different genetic backgrounds were distributed across various geographic regions. On the other hand, there were cases where samples from the same or neighboring zones occurred in the same cluster which could imply that material exchange was stronger among neighbouring regions than among those distantly apart. Grouping of grass pea accessions from different origins in the same group was also previously reported using morphological markers (Tadesse \& Bekele 2003).

Breeding system, gene flow, isolation mechanisms and intensive selection by natural and experimental pressures can influence the genetic structure of a population (Chandel \& Joshi 1983). In our study, the $\mathrm{f}=0$ model could be considered as likely as the Full model, since the difference in Dbar values between these two models was low (0.59), hence inbreeding is an unlikely driving force in determining the structure in the studied population (Holsinger \& Lewis 2006). The low level of differentiation among accessions, which accounted for only $7 \%$ of the total variation observed here, could result from seed exchange among farmers and human relocation. It could also be attributed to the type of marker used since EST-SSRs showed higher differentiation $\left(\mathrm{F}_{\mathrm{ST}}=0.15, \mathrm{P}<0.001\right)$ value (Shiferaw et al. 2012).

To our knowledge, this is the first attempt to apply CAPS markers for diversity assessment in L. sativus. The set of CAPS markers employed in this study demonstrates the utility of such markers for genetic diversity analysis. Similar markers can be developed from newly developed DNA sequences for the species (Lioi \& Galasso 2013; Yang et al. 2014) available in the public database. These markers could be useful for examining patterns of genetic diversity in grass pea accessions across a wider scope of geographical locations. The requirement of relatively cheap equipment and procedures, which include PCR, digestion with restriction enzymes and simple identification of fragments after digestion resolved by agarose gel electrophoresis is an advantageous property of CAPS markers. They can be exploited as alternative molecular markers either individually or in combination with other marker types in species that lack sufficient molecular tools. 
Acknowledgements. We acknowledge the Ethiopian Biodiversity Institute for providing the accessions used in this study. This work was financially supported by the Interna- tional Doctoral Programme in Agrobiodiversity of Scuola Superiore Sant'Anna, Pisa, Italy. The authors are thankful to the anonymous reviewers for their valuable comments.

\section{References}

Akashi Y., Shiomi S., Kubo Y., Masuda M. \& Kato K. 2001. Microsatellite and CAPS markers for ethylene-related genes, (1-Aminocyclopropane-1-caroxylic Acid ACC) synthase and ACC oxidase genes, and their variation in Melon (Cucumis melo L.). Breeding Sciences 51: 107-112.

Barth S., Melchinger A. E. \& Bberstedt T. L. 2002. Genetic diversity in Arabidopsis thaliana (L.) Heynh. investigated by cleaved amplified polymorphic sequence (CAPS) and Inter-Simple Sequence Repeat (ISSR) markers. Mol Ecol 11: 495-505.

Belaid Y., Chtourou-Ghorbel N., Marrakchi M. \& TrifiFARAH N. 2006. Genetic diversity within and between populations of Lathyrus genus (Fabaceae) revealed by ISSR markers. Genet Resour Crop Ev 53: 1413-1418.

Campbell C.G. 1997. Grass pea. Lathyrus sativus L. Promoting the conservation and use of underutilized and neglected crops. 18. Institute of Plant Genetics and Crop Plant Research, Gatersleben/International Plant Genetic Resources Institute, Rome, Italy.

Chandel K. P. S. \& Joshi B. S. 1983. Multivariate analysis in green-seeded pea. Indian J Agr Sci 53: 198-200.

Chowdhury M. A. \& Slinkard A. E. 2000. Genetic diversity in grass pea (Lathyrus sativus L.). Genet Resour Crop Ev 47: 163-169.

Chtourou-Ghorbel N., Lauga B., Combes D. \& Marrakchi M. 2001. Comparative genetic diversity studies in the genus Lathyrus using RFLP and RAPD markers. Lathyrus Lathyrism Newsletter 2: 62-68.

Croft A. M., Pang E. C. K. \& TAYlor P. W. J. 1999. Molecular analysis of Lathyrus sativus L. (grass pea) and related Lathyrus species. Euphytica 107: 167-176.

CSA 2016. Agricultural sample survey 2015/2016. Report on area and production of crops volume I. Central Statistics Authority (CSA), Addis Ababa, Ethiopia.

Gutierrez N., Avila C. M., Duc G., Marget P., Suso M. J., Moreno M. T. \& Torres A. M. 2006. CAPs markers to assist selection for low vicine and convicine contents in faba bean (Vicia faba L.). Theor Appl Genet 114: 59-66.

Holsinger K. E. \& Lewis P. O. 2006. HICKORY: A package for analysis of Population Genetic data v1.0.4. Department of Ecology and Evolutionary Biology, University of Connecticut, Storrs, USA.

Hu C., Tsai Y. \& Lin 2014. Development of STS and CAPS markers for variety identification and genetic diversity analysis of tea germplasm in Taiwan. Bot Stud 55:12.

Konieczny A. \& Ausubel F. M. 1993. A procedure for mapping Arabidopsis mutations using co-dominant ecotype-specific PCR-based markers. Plant J 4: 403410.
Konovalov R., Toshchakova E. \& Gostimsky S. 2005. A CAPS marker set for mapping in linkage group III of pea Pisum sativum L.). Cell Mol Biol Lett 10(1): 163-71.

Lioi L. \& Galasso I. 2013. Development of genomic simple sequence repeat markers from an enriched genomic library of grass pea (Lathyrus sativus L.). Plant breeding. Doi:10.1111/pbr.12093

Miller M. P. 1997. Tools for population genetic analysis (TFPGA): A windows program for the analysis of allozyme and molecular population genetic data. Freely available from: http://bioweb.usu.edu/mpmbio/ index.htm

NeI M. 1972. Genetic distance between populations. Am Nat 106: 283-292.

Peakall R. \& Smouse P. E. 2012. GenAlEx 6.5: genetic analysis in Excel. Population genetic software for teaching and research - an update. Bioinformatics 28: 2537-2539. Freely available from: http://bioinforma tics.oxfordjournals.org/content/28/19/2537.

Shiferaw E., Pè E., Porceddu M. E. \& Ponnaiah M. 2012. Exploring the genetic diversity of Ethiopian grass pea (Lathyrus sativus L.) using EST-SSR markers. Mol. Breeding 30: 789-797.

Skiba B., Ford R. \& PAng E. C. K. 2003. Amplification and detection of polymorphic Sequence-Tagged Sites in Lathyrus sativus. Plant Mol Biol Rep 21: 391-404.

Smartt J., Kaul A., Araya W. A., Rahman M. M. \& Kearney J. 1994. Grass pea (Lathyrus sativus L.) as a potentially safe food legume crop. In: F. J. MueHLBAUER \& W. J. KAISER (eds.). Expanding the production and use of cool season food legumes, pp. 144-155. Kluwer Academic Publishers, Dordrecht, The Netherlands.

Sun X., Yang T. , Guan J., Ma Y., Jiang J., Cao R., Burlyaeva M. , Vishnyakova M., Semenova E., Bulyntsev S. \& ZoNG X. 2012. Development of 161 novel EST-SSR markers from Lathyrus sativus (Fabaceae). Am J Bot 99: 379-390.

Tadesse W. \& Benele E. 2003. Phenotypic diversity of Ethiopian grass pea (Lathyrus sativus L.) in relation to geographical regions and altitudinal range. Genet Res Crop Ev 50: 497-505.

Tavoletti S. \& Iommarini L. 2007. Molecular marker analysis of genetic variation characterizing a grass pea (Lathyrus sativus) collection from central Italy. Plant Breeding 1266: 607-611.

Tsumura Y. \& TOMARU N. 1999. Genetic diversity of Cryptomeria japonica using co-dominant DNA markers based on sequenced tagged site. Theor Appl Genet 98: 396-404.

Tsumura Y., Matsumoto A., Tani N., Ujino-Ihara T., Kado T., Iwata H. \& Uchida K. 2007. Genetic diversity 
and the genetic structure of natural populations of Chamaecyparis obtusa: implications for management and conservation. Heredity 99: 161-172.

Varshney R.K., Chabane K., Hendre P. S., Aggarwal R. K. \& Graner A. 2007. Comparative assessment of EST-SSR, EST-SNP and AFLP markers for evaluation of genetic diversity and conservation of genetic resources using wild, cultivated and elite barleys. Plant Sci 173: 638-649.

Vaz Patto M. C., Skiba B., Pang E. C. K., Ochatt S. J., Lambein F. \& Rubiales D. 2006. Lathyrus improvement for resistance against biotic and abiotic stresses:
From classical breeding to marker assisted selection. Euphytica 147: 133-147.

Wang F., Yang T., Burlyaeva M., Li L., Jiang J., Fang L., REDDEN R. \& Zong X. 2015. Genetic diversity of grass pea and its relative species revealed by SSR markers. PLoS ONE 10(3): e0118542. Doi:10.1371/journal. pone. 0118542 .

Yang T., Jiang J., Burlyaeva M., Hu J., Coyne C. J., Kumar S. , Redden R. , Sun X., Wang F., Chang J., Hao X., GuAn J. \& Zong X. 2014. Large-scale microsatellite development in grass pea (Lathyrus sativus L.), an orphan legume of the arid areas. BMC Plant Biol 14: 65. 